ORIGINAL ARTICLE

\title{
Observational study of the extent of driving while suspended for alcohol impaired driving
}

\author{
A T McCartt, L L Geary, A Berning
}

Injury Prevention 2003;9:133-137

\begin{abstract}
Objective: To determine the proportion of first time driving while alcohol impaired (DWI) offenders who drive while their driver's license is suspended.

Design: Systematic, unobtrusive observations were conducted by surveillance professionals from Pinkerton Investigative Services, Inc, of first time offenders in the City of Milwaukee, Wisconsin, and Bergen County, New Jersey. Observations included two four hour periods during suspension (one weekday morning, one Friday/Saturday evening) and two four hour periods after license reinstatement (matched by day of week and time of day). Focus groups of first time offenders were conducted in each site.

Setting: New Jersey laws pertaining to license suspension for DWI and driving while suspended are stronger than Wisconsin laws.

Subjects: 93 recently convicted first time DWI offenders (57 in Milwaukee and 36 in Bergen County). Main outcome measures: Proportion of subjects observed driving during suspension and after license reinstatement, with reference to all subjects and subjects observed traveling by any means. Results: Of subjects observed traveling while suspended, $88 \%$ of Milwaukee subjects compared with $36 \%$ of Bergen County subjects drove. Five percent of Milwaukee subjects and $78 \%$ of Bergen County subjects reinstated their driver's license. Bergen County subjects were significantly more likely to drive after reinstatement (54\%) than during suspension (25\%).

Conclusion: Prevalence of driving while suspended among first time offenders is high and can vary substantially between jurisdictions. However, the license suspension can have a positive impact on the driving patterns of offenders during suspension, relative to after license reinstatement. Lower prevalence of driving while suspended in New Jersey may partly be attributable to that state's tougher laws.
\end{abstract}

\author{
See end of article for \\ authors' affiliations \\ Correspondence to: \\ A \\ Safety, 1005 North Glebe \\ Road, Arlington, VA \\ amccartt@iihs.org
} wenty years of research has shown that removal of the driver's license is an effective deterrent for alcohol impaired driving (DWI). ${ }^{1-5}$ State laws provide for license suspension/revocation after conviction for DWI. Implied consent laws allow license suspension/revocation for refusal to submit to a blood alcohol concentration (BAC) test. The large majority of states have administrative license revocation/ suspension laws that allow police and licensing authorities to remove the license before conviction, based on a BAC test failure (BAC $\geqslant 0.08 \%$ or $0.10 \%$ ) or refusal. In many jurisdictions, offenders may obtain an occupational license permitting limited driving during part or all of the suspension period. ${ }^{6}$

There is evidence that some DWI offenders continue driving after license withdrawal. ${ }^{5-10}$ Of US fatal crashes occurring from 1993-97, 6\% involved a driver whose license was suspended/revoked; $27 \%$ of these drivers had at least one DWI conviction during the three years preceding the crash. DeYoung et al estimated that drivers who license was suspended/revoked comprised $9 \%$ of California drivers and were over-involved in fatal crashes by a factor of 3.7:1. ${ }^{11}$ In roadside checkpoints in Canada, the percentage of persons driving while suspended/revoked (DWS/DWR) for any reason $(1.5 \%)$ was $57 \%$ of the expected value relative to their representation among all drivers $(2.7 \%)$. Canadian DWI offenders under-represented their own incidence of DWS/ DWR, and the majority reported driving more carefully during suspension. ${ }^{12}$

Conducting observational research to establish the prevalence of DWS/DWR among convicted DWI offenders has been precluded by the considerable logistical challenges involved. This study represents the first systematic effort to gather objective, independent, and unobtrusive observational data on travel by persons whose license is suspended for DWI. The research, conducted fall 2000 to fall 2001 in two sites located in different states, encompassed focus group research and an observational study conducted in association with Pinkerton Investigation Services, Inc.

\section{METHODS}

\section{Study sites}

The primary criteria for selecting sites were related to the following data requirements: a representative sample of first time DWI convictions falling within a specified recent time period; timely, detailed case level court data on DWI offenders, including driver's license identification numbers; and driver records from the state's licensing agency available in a timely, affordable manner. Few jurisdictions could meet these data requirements. Jurisdictions also were sought where the large majority of first time DWI offenders experienced a "hard" license suspension (that is, no occupational license) of sufficient length so that observations could be conducted, and where most residents relied on their vehicle for transportation. Sites needed to be in close proximity to Pinkerton offices, located in major metropolitan areas throughout the country. To the extent possible, sites with contrasting socioeconomic profiles were sought.

The two study sites were the City of Milwaukee, Wisconsin, and Bergen County, New Jersey. During the study period, both

Abbreviations: BAC, blood alcohol concentration; DWI, driving while impaired by alcohol; DWS/DWR, driving while license suspended/ revoked 
Table 1 New Jersey and Wisconsin laws relating to license suspension penalties for first time standard DWI offense and penalties for first time driving while suspended for DWI for persons 21 years and older

\begin{tabular}{|c|c|c|}
\hline & New Jersey & Wisconsin \\
\hline \multicolumn{3}{|l|}{ First time DWI } \\
\hline Administrative license sanction & None & $\begin{array}{l}\text { BAC } \geqslant 0.10 \% \text { : mandatory } 6 \text { month suspension, } \\
\text { effective } 30 \text { days after arrest } \\
\text { Test refusal: mandatory } 1 \text { year revocation, effective } \\
30 \text { days after arrest }\end{array}$ \\
\hline Court imposed license sanction & $\begin{array}{l}6 \text { - } 12 \text { month suspension (mandatory } 6 \text { months); } \\
\text { additional non-current mandatory } 6 \text { month } \\
\text { revocation for test refusal }\end{array}$ & $\begin{array}{l}\text { 6-9 month suspension (mandatory } 6 \text { months), } \\
\text { served concurrently with administrative suspension }\end{array}$ \\
\hline Occupational driver license & None & $\begin{array}{l}\text { Available to all } 1 \text { st offenders unless license was } \\
\text { suspended/revoked within prior year }\end{array}$ \\
\hline \multicolumn{3}{|l|}{ First time driving while suspended/revoked } \\
\hline Offense & Driving while suspended/revoked for DWI & $\begin{array}{l}\text { Operating while suspended/revoked; no special } \\
\text { penalties if suspension based on DWI }\end{array}$ \\
\hline Jail & 10-90 days & $\begin{array}{l}\text { None for operating while suspended; } \leqslant 1 \text { year for } \\
\text { operating while revoked }\end{array}$ \\
\hline Fine & $\begin{array}{l}\text { Mandatory minimum } \$ 500 \text { and } \$ 250 / \text { year } \\
\text { insurance surcharge for } 3 \text { years }\end{array}$ & $\begin{array}{l}\text { Not mandatory: driving while suspended } \$ 50-250 \text {; } \\
\text { driving while revoked } \leqslant \$ 2500\end{array}$ \\
\hline License suspension & $1-2$ years added suspension (mandatory 1 year) & $\leqslant 6$ months at court's discretion \\
\hline Vehicle sanction & $\begin{array}{l}\text { Registrations of offender's vehicles revoked for same } \\
\text { period as license suspension; may issue temporary } \\
\text { license tags for specified uses by other drivers }\end{array}$ & $\begin{array}{l}\text { May impound offender's vehicles at discretion of } \\
\text { court }\end{array}$ \\
\hline
\end{tabular}

Note: the table summarizes laws in effect 2000-01, based on National Highway Traffic Safety Administration's Digest of State Alcohol-Highway Safety Related Legislation. 19th Edition, current as of 1 January 2000; 1999 Wisconsin Alcohol Traffic Safety Facts Book; and websites http://www.njleg.nj.us/ $\mathrm{html} /$ statutes.htm and http://www.legis.state.wi.us/rsb/stats.html.

Wisconsin and New Jersey had a $0.10 \%$ BAC per se law, a 10 year "look back" period for defining repeat DWI offenses, and a requirement that all DWI offenders participate in an alcohol education/assessment program. ${ }^{6}$

The states' laws differed with regard to driver's license penalties for first time DWI offenses and penalties for DWS/DWR for DWI (table 1). Wisconsin imposed mandatory minimum administrative and court suspension penalties for first time DWI offenses. For eligible offenders, an occupational license was available. This permitted driving for specified times (for example, daytime hours), routes (for example, within 40 mile radius of residence), and purposes (for example, to/from work). Statewide data from the Wisconsin Division of Motor Vehicles indicated that most first time DWI offenders did not obtain an occupational license. There were neither mandatory minimum penalties for DWS/DWR nor special sanctions for DWS/DWR based on a DWI offense. New Jersey had no administrative license sanctions. Upon conviction, first time offenders received a mandatory minimum "hard" license suspension with no occupational license available. There were substantial mandatory penalties for DWS/DWR for DWI.

The sociodemographic profiles of the two sites differ considerably (2000 US census). The City of Milwaukee has 596974 residents. The median annual household income in 1999 was $\$ 32$ 216. The city's population includes 38\% AfricanAmerican, $12 \%$ Hispanic or Latino, 3\% Asian, and 2\% Native American residents. Bergen County is a densely populated county in northern New Jersey with a population of 884118 The median annual household income in 1999 was \$65 241 . The primary minority groups include Asian ( $11 \%$ ), Hispanic or Latino (10\%), and African-American (5\%) residents. Bus service is the primary mode of public transportation in Milwaukee; bus and train service is available in Bergen County.

\section{Observational study method}

Trained and bonded surveillance professionals from Pinkerton Investigation Services, Inc, observed drivers during their license suspension and if their license was reinstated, again after the suspension ended, to document travel to or from their residence. Comparison of travel during and after the suspension period permitted inferences to be drawn concerning whether an offender's travel patterns changed as a result of the suspension.

\section{Selection of subjects}

Subjects were persons who had recently been convicted of a "standard" first time DWI offense, were 21 years of age or older, and resided in-state within a 50 mile radius of Milwaukee or Bergen County.

Case records were obtained from the Milwaukee Municipal Court and from five Bergen County municipal courts for all qualified DWI offenders whose dates of conviction fell within specified time periods such that license suspensions would end during fall 2000 to fall 2001. The dates of the suspension and subjects' eligibility for license reinstatement were determined from driver record abstracts. For subjects eligible for license reinstatement, a second driver abstract was obtained one to two months after the suspension ended to determine whether and when reinstatement had occurred.

Of the initial pool of 130 Milwaukee offenders for whom court records were obtained, $80(62 \%)$ were eligible to obtain an occupational license; 33 (25\%) did so. The driver records revealed that occupational licenses generally allowed driving during all but a few hours of the day; thus, offenders with occupational licenses were excluded. Compared with the total pool of 130 offenders, persons with occupational licenses were more likely to be 55 years or older $(21 \% v 8 \%)$ and less likely to have had at least one license suspension before the DWI arrest $(33 \%$ v $52 \%)$.

A few potential subjects were excluded because observations were impossible or unfeasible. This included, for example, persons who could not be located, had moved out of state, were incarcerated, or lived in an apartment complex. Observations were conducted of all remaining subjects for whom court records had been obtained: 57 Milwaukee offenders and 36 Bergen County offenders. Thus, among the offenders for whom court case records were obtained, all who met the subject criteria, and the additional study requirements described above, were subjects. Subjects were all offenders who qualified for the study, and not a sample of these offenders.

\section{Protocol}

Subjects were observed for four hours during the last month of their suspension period on one randomly selected weekday morning (Monday to Thursday, 6-10 am) and one randomly selected weekend evening (Friday or Saturday, 6-10 pm). Drivers who reinstated their license were observed on the 
same weekday morning and weekend evening one to two months after reinstatement. Drivers whose license was not reinstated were observed only during suspension.

In accordance with Pinkerton's standard procedures, investigators verified that subjects currently resided at the address of record and were at home before the scheduled observation. Physical descriptions of subjects were available from court and driver records. Subjects were counted as observed only if the investigator was certain that the person observed was the subject. No person-to-person contact with subjects occurred When observing a residence, the investigator remained in a vehicle parked on the public street. If subjects left their residence, the investigator attempted to follow them unobtrusively. Data for each observation included the date and time; whether the subject was observed traveling; and if so, whether driving, walking, riding as a passenger, destination of travel if known, and passenger information. Any documentation containing identifying information about subjects was destroyed

\section{Analyses}

The key study measure was the proportion of subjects observed driving during one or both of the observation periods during the suspension period. The proportions were compared for the two sites $\left(\chi^{2}\right.$ statistic, $\left.\mathrm{p}<0.05\right)$. For subjects who reinstated their license, the proportion who drove during the suspension period was compared to the proportion driving after reinstatement.

\section{Method for focus group research}

Focus groups were used to gather qualitative information on the knowledge, behaviors, and attitudes of recently convicted first time DWI offenders, recruited from participants in the required alcohol/drug education programs. Focus groups conducted during summer 2001 included 16 participants in Milwaukee and 21 participants in Bergen County. Most participants in both sites were currently under suspension; the others had reinstated their license. Eleven Milwaukee participants had an occupational license.

\section{RESULTS}

\section{Observational study}

Subjects' characteristics, driving records, current DWI offense

Subject characteristics differed between sites (table 2). A larger proportion of Bergen County subjects were 25 years old or younger $(31 \% v 18 \%)$ and female $(25 \% v 11 \%)$. Over half the Milwaukee subjects resided in areas with median annual household income less than $\$ 35$ 000; by contrast, two thirds of Bergen County subjects resided in areas with median income of $\$ 70000$ or more. Milwaukee subjects were more likely to have had at least one non-DWI traffic violation $(72 \% v 56 \%)$ or at least one non-DWI related suspension ( $67 \% v 17 \%)$ during the five years preceding the current DWI arrest, or at least one suspension when arrested ( $47 \% v 6 \%)$. In both sites, about half the prior suspensions were due to unpaid fines/fees, and half were due to a poor driving record or driving without a valid license or vehicle registration.

Seven (19\%) Bergen County subjects received at least one suspension subsequent to their DWI conviction. Most suspensions were related to unpaid fines/fees; for two subjects, the suspension followed a DWS conviction. Forty eight Milwaukee subjects $(84 \%)$ received at least one subsequent suspension. Almost all these suspensions related to the DWI conviction, and were due to failure to comply with the alcohol assessment/education requirement or unpaid fines/fees. Five suspensions were based on DWS/DWR or driving with revoked vehicle registration.

\section{Results of observations}

Of the 57 Milwaukee subjects, 30 (53\%) drove while suspended during one or both of the observation periods, four
Table 2 Characteristics and driving records of observational study subjects; values are percent

\begin{tabular}{|c|c|c|}
\hline & $\begin{array}{l}\text { Milwaukee } \\
(n=57)\end{array}$ & $\begin{array}{l}\text { Bergen County } \\
(n=36)\end{array}$ \\
\hline \multicolumn{3}{|l|}{ Age (years) } \\
\hline $21-25$ & 17.5 & 30.6 \\
\hline $26-34$ & 35.1 & 22.2 \\
\hline $35-54$ & 43.9 & 36.1 \\
\hline$\geqslant 55$ & 3.5 & 11.1 \\
\hline \multicolumn{3}{|l|}{ Gender } \\
\hline Female & 10.5 & 25.0 \\
\hline Male & 89.5 & 75.0 \\
\hline \multicolumn{3}{|c|}{ Median annual household income of residential zip code } \\
\hline$<\$ 35000$ & 54.4 & - \\
\hline$\$ 35000-\$ 44999$ & 26.3 & 5.6 \\
\hline$\$ 45000-\$ 54999$ & 15.8 & 13.9 \\
\hline$\$ 55000-\$ 69999$ & 3.5 & 13.9 \\
\hline$\geqslant \$ 70000$ & - & 66.7 \\
\hline \multicolumn{3}{|c|}{ Non-DWI traffic violations in 5 years before current DWI offense } \\
\hline None & 28.1 & 44.4 \\
\hline $1-3$ & 35.1 & 47.2 \\
\hline$\geqslant 4$ & 36.9 & 8.3 \\
\hline \multicolumn{3}{|c|}{ Non-DWI license suspensions in 5 years before current DWI offense } \\
\hline None & 33.3 & 83.3 \\
\hline 1 & 14.0 & 5.6 \\
\hline$\geqslant 2$ & 52.7 & 11.1 \\
\hline \multicolumn{3}{|c|}{ Suspensions in effect on date of current DWI arrest } \\
\hline None & 52.6 & 94.4 \\
\hline 1 & 19.3 & 2.8 \\
\hline$\geqslant 2$ & 28.1 & 2.8 \\
\hline
\end{tabular}

Table 3 Observed travel during license suspension period; Milwaukee and Bergen County; values are percent (number)

\begin{tabular}{|c|c|c|}
\hline & $\begin{array}{l}\text { Milwaukee } \\
(n=57)\end{array}$ & $\begin{array}{l}\text { Bergen } \\
\text { County } \\
(n=36)\end{array}$ \\
\hline Drove at least once & $52.6(30)$ & $22.2(8)$ \\
\hline Did not drive and used alternative travel & $7.0(4)$ & 38.9 (14) \\
\hline Travel not observed & $40.4(23)$ & $38.9(14)$ \\
\hline
\end{tabular}

(7\%) did not drive but used alternative transportation on at least one occasion, and $23(40 \%)$ did not travel during either observation (table 3 ). Of the 36 Bergen County subjects, eight $(22 \%)$ drove while suspended during one or both observation periods, $14(39 \%)$ did not drive but used alternative transportation, and $14(39 \%)$ did not travel. Between-site differences were statistically significant $(\mathrm{p}<0.001)$.

Of 34 Milwaukee subjects who traveled by any means during either of the two during suspension observations, 30 $(88 \%)$ drove at least once (table 4$)$. Of 22 Bergen County subjects observed traveling, eight (36\%) were observed driving on at least one occasion. The between-sites differences were significant $(\mathrm{p}<0.001)$.

Twenty three $(40 \%)$ of the 57 Milwaukee subjects were eligible to reinstate their license after the DWI suspension; only three $(5 \%)$ did so. Thus, comparison of during suspension/ after suspension travel patterns of Milwaukee subjects yielded little useful information. All 36 Bergen County subjects were eligible for reinstatement, and $28(78 \%)$ reinstated. Among subjects who reinstated, $25 \%$ drove and $43 \%$ used alternative transportation during their suspension, versus $54 \%$ and $7 \%$, respectively, after reinstatement $\left(\chi^{2}=10.3, \mathrm{p}<0.001, \mathrm{df}=2\right)$ (table 5).

For Milwaukee subjects, DWS was about equally likely on weekday mornings (28\%) or Friday/Saturday evenings (32\%). DWS among Bergen County subjects was more common on 
Table 4 Method of travel for subjects observed traveling during license suspension period; Milwaukee and Bergen County; values are percent (number)

\begin{tabular}{lll}
\hline & $\begin{array}{l}\text { Milwaukee } \\
(\mathrm{n}=34)\end{array}$ & $\begin{array}{l}\text { Bergen } \\
\text { County } \\
(\mathrm{n}=22)\end{array}$ \\
\hline $\begin{array}{lll}\text { Drove at least once } \\
\text { Did not drive and used alternative travel }\end{array}$ \\
\hline $11.2(30)$ & $36.4(8)$ \\
\hline$\chi^{2}=16.5, p<0.001, d f=1$. & $63.6(14)$ \\
\hline
\end{tabular}

Table 5 Observed travel during suspension and after reinstatement for Bergen County subjects whose license was reinstated; values are percent (number)

\begin{tabular}{lll}
\hline & $\begin{array}{l}\text { During } \\
\text { suspension } \\
\text { (n=28) }\end{array}$ & $\begin{array}{l}\text { After } \\
\text { reinstatement } \\
(\mathbf{n}=28)\end{array}$ \\
\hline Drove at least once & $25.0(7)$ & $53.6(15)$ \\
Did not drive and used alternative travel & $42.9(12)$ & $7.1(2)$ \\
Travel not observed & $32.1(9)$ & $39.3(11)$ \\
\hline$\chi^{2}=10.3, p<0.001, d f=2$. & & \\
\hline
\end{tabular}

Friday/Saturday evenings ( $19 \% v 6 \%$ ); driving after reinstatement was about equally likely on weekday mornings $(32 \%)$ or Friday/Saturday evenings (36\%). In either location, when subjects traveled but did not drive, they most commonly rode as a passenger in a passenger vehicle.

\section{Potential factors affecting driving while suspended}

Key driver related variables were examined for within-site effects on DWS. Small samples limited the ability to identify statistically significant relationships; any patterns should be regarded only as suggestive of a relationship. Neither age nor gender had a consistent relationship to DWS. Median annual incomes did not appear to be a factor in Bergen County. In Milwaukee, DWS was more prevalent among subjects living in areas with median annual incomes less than $\$ 25000$ (73\% v $45 \%)$. DWS was more likely among Milwaukee subjects who had a prior license suspension ( $82 \% v 62 \%)$ or were suspended when arrested for DWI ( $81 \%$ v $68 \%)$.

\section{Summary of focus groups}

Based on focus group discussions, financial penalties reported by Bergen County participants were much more severe, on average, than those reported by Milwaukee participants. Reported license sanctions also were more severe in New Jersey, on average, as Wisconsin's license penalties were weakened by availability of the occupational license. Bergen County participants had a higher perceived risk of detection for DWS and a greater knowledge and fear of the DWS sanctions. License suspension represented a substantial hardship for New Jersey participants; many reported major changes in their work and personal lives. Few Milwaukee participants reported significant accommodations to reduce their dependence on driving. Thus, license sanctions in New Jersey, relative to those in Wisconsin, apparently had considerable deterrent power, but were viewed as more onerous.

A sizeable proportion of participants in both sites indicated that they drove while suspended on at least some occasions. Most Milwaukee participants with an occupational license reported driving illegally on at least some occasions.

\section{DISCUSSION}

To date, evidence that DWI offenders continue to drive after license withdrawal has relied largely on drivers' self report or on rates of rearrest for DWI, traffic violations, or crash involvement. This study reports the first objective, independent, unobtrusive observational data on the extent of DWS by DWI offenders. In all, 1000 hours of observational data were collected.

Three key findings emerged. First, prevalence of DWS among first time offenders was high. As subjects were observed only for two four hour periods during suspension, the extent of driving throughout the entire suspension period was likely much higher. Second, the prevalence of DWS differed between sites; compliance with the license suspension was dramatically higher in Bergen County. Assuming that subjects were typical offenders, and that observations were conducted on typical weekday mornings and Friday/Saturday evenings, the study suggests that $28 \%$ of Milwaukee offenders and $6 \%$ of Bergen County offenders drove while suspended on a typical weekday morning and 32\% of Milwaukee offenders and $19 \%$ of Bergen County offenders drove while suspended on a typical weekend evening. Third, based on Bergen County drivers who reinstated their license, the suspension appeared to reduce driving during the suspension, relative to driving after reinstatement, when typical driving patterns presumably would have been resumed.

In addition to small samples, there were other study limitations. Although sites with different socioeconomic profiles were sought, these differences limited the examination of other factors. Another limitation was inherent in the innovative observation method. Although great care was taken to ensure that subjects were correctly identified by investigators, the possibility that a subject was mistakenly identified cannot be eliminated with total certainty.

Focus group participants were volunteers, introducing a potential selection bias, and persons who failed to attend the alcohol/drug classes were excluded. The Milwaukee focus groups were limited to offenders determined by an alcohol assessment to be "irresponsible drinkers"; offenders determined to have more serious alcohol problems were excluded.

There are likely several explanations for between-site differences in observed DWS. One consideration is the different socioeconomic profiles of the two sites; Bergen County subjects were more likely to live in affluent areas. Although effects of income on DWS could not be determined due to small samples and the lack of case level income data, more affluent persons may be better able to maintain their work and social lives without driving illegally. The lack of case level data on subjects' places of employment or proximity to public transportation limited examination of these factors. Another consideration is that Milwaukee is a large city and Bergen County is comprised of small municipalities and boroughs. Focus group participants in Bergen County believed that local police officers knew them and were aware of their DWI conviction. Clearly, there is more anonymity in a large city. Enforcement priorities also may differ between a smaller, more residential community and a large city.

Milwaukee subjects, in general, had more problematic driving histories. Although a statistical relationship could not be verified, observed DWS in Milwaukee was higher among subjects with prior license suspensions. For Milwaukee subjects with multiple suspensions extending far into the future, restoration of driving privileges may have seemed remote or even unlikely.

As Milwaukee offenders with occupational licenses were excluded from observations, the sample did not represent all offenders. Yet, one third of persons with occupational licenses had at least one prior license suspension, and many focus group participants with occupational licenses indicated that they sometimes drove illegally.

Future studies may wish to examine the role of economic factors in accumulating poor driving histories and multiple suspensions. Many Milwaukee subjects had multiple license suspensions, usually based on unpaid pay fines/fees. The focus 


\section{Key points}

- Surveillance professionals gathered observational data on travel patterns of first time DWI offenders whose driver's licenses were suspended.

- Travel patterns of offenders in two sites were observed during suspension and after license reinstatement.

- Prevalence of driving while suspended was high in both sites, but was substantially higher in one site.

- In the site where license reinstatement was common, driving was more likely after reinstatement than during suspension.

- Lower prevalence of driving while suspended may be due in part to tougher DWI laws and enforcement.

groups suggested that insurance costs were a consideration for some Milwaukee offenders in deciding whether to obtain an occupational license, and were a consideration in both sites regarding license reinstatement. Some participants expressed difficulty in affording the alcohol education/assessment classes.

The focus group discussions suggest another important factor in between-site differences in DWS: the relative severity of DWI laws and associated perceptions and behaviors. The lack of an occupational license in New Jersey meant that the license suspension had a greater impact on offenders' work and personal lives, and, thus, was a stronger deterrent. Although Milwaukee participants with an occupational license acknowledged that they drove outside the license restrictions, they also indicated that most driving could be done within these restrictions. In New Jersey, where there were more severe penalties for DWS, there also was a markedly higher perceived risk of apprehension and punishment for DWS. Thus, although the study confirms that the prevalence of DWS is high, it also suggests that strong state laws, coupled with a high level of perceived enforcement, may increase compliance.

\section{ACKNOWLEDGEMENTS}

The US National Highway Traffic Safety Administration funded this study.

\section{Authors' affiliations}

A T McCartt, L L Geary, Preusser Research Group, Inc, Trumbull, Connecticut

A Berning, National Highway Traffic Safety Administration, Washington

\section{REFERENCES}

1 Wagenaar AC, Zobek TS, Williams GD, et al. Effects of DWI control efforts: a systematic review of the literature from 1960-1991. Minneapolis, MN: University of Minnesota, School of Public Health, Minneapd 2000.

2 Peck RC. The general and specific deterrent effects of DUI sanctions: a review of California's experience. Alcohol, Drugs and Driving $1991 ; 7: 13-42$

3 Klein T. Changes in alcohol-involved fatal crashes associated with tougher state alcohol legislation. Contract DTNH22-88-C745.

Washington, DC: National Highway Traffic Safety Administration, 1987

4 Preusser DF, Blomberg RD, Ulmer RG. Evaluation of the 1982 Wisconsin drinking and driving law. J Safety Res 1995;19:29-40. 5 Peck RC, Sadler DD, Perrine MW. The comparative effectiveness of alcohol rehabilitation and licensing control actions for drunk driving offenders: a review of the literature. Alcohol, Drugs and Driving 1985;1:15-20.

6 National Highway Traffic Safety Administration. Digest of state alcohol-highway safety related legislation. 19th Ed. Washington, DC: NHTSA, 2001

7 Griffin LI, DeLaZerda S. Unlicensed to kill. Washington, DC: AAA Foundation for Traffic Safety, 2000

8 Wiliszowski C Murphy $\mathrm{P}$, Jones $\mathrm{R}$, et al. Determine reasons for repeat drinking and driving. DOT HS 808 401. Washington, DC: National Highway Traffic Safety Administration, 1996.

9 Ross HL, Gonzales P. Effects of license revocations on drunk-driving offenders. Accid Anal Prev 1995;20:379-91.

10 Jones B. Oregon's habitual traffic offender program: an evaluation of the effectiveness of license revocation. I Safety Res 1987:88:19-26.

11 DeYoung DJ, Peck RC, Helander CJ. Estimating the exposure and fatal crash rates of suspended/revoked and unlicensed drivers in California. Accid Anal Prev 1997;29:17-23.

12 Malenfant JEL, Van Houten R, Jonah B. A study to measure the incidence of driving under suspension in the Great Moncton area. Accid Anal Prev 2002;34:439-47. 